\title{
The Influence of Carl Rogers' Humanism on the Development of Positive Attitudes in Medical Students
}

\author{
Clóvis Luís Konopka1 ${ }^{*}$, Martha Bohrer Adaime ${ }^{2}$, Clediane Cunha ${ }^{1}$, Alice Dias ${ }^{1}$ \\ ${ }^{1}$ Faculty of Medicine, Federal University of Santa Maria, Santa Maria, Brazil \\ ${ }^{2}$ Faculty of Chemistry, Federal University of Santa Maria, Santa Maria, Brazil \\ Email: "cloviskonopka@gmail.com
}

Received 15 July 2015; accepted 20 November 2015; published 23 November 2015

Copyright (C) 2015 by authors and Scientific Research Publishing Inc.

This work is licensed under the Creative Commons Attribution International License (CC BY).

http://creativecommons.org/licenses/by/4.0/

(c) (i) Open Access

\begin{abstract}
The medical school has the purpose of comprehensively training competent undergraduate students by developing their knowledge, skills and attitudes. However, the best way to teach them attitudes has not yet been established, and many schools delegate this mission to humanistic disciplines. There are few reports regarding the influence of humanism on the development of attitudes, fact that increases the difficulty in integrating humanistic themes to teaching purposes in health. The current paper analyzes the influence of Carl Rogers' humanistic conception on the attitudes of a sample comprising medical school students from the Federal University of Santa Maria, under five dimensions (knowledge, ambience, ethical, social and belief). The results showed that the Rogerian intervention significantly influenced the development of positive attitudes within the "belief" dimension. There was increase in the attitude score in all dimensions, showing positive tendency between the beginning and end of the study. The students whose profile showed positive attitudes in all dimensions were from the female gender, whose fathers and mothers had higher education degree. These students also used books and journals as complementary source of studies and dedicated a time equal to or greater than six hours per week to study. It can be concluded that Carl Rogers' humanistic principles may be properly used without causing discomfort or threat to both the students and the teacher. The student-centered teaching is not a method or a theory, but a style in the teacher-student relationship, in which the formative aspect outweighs the informative one.
\end{abstract}

\section{Keywords}

Medical Education, Humanism, Attitude, Student-Centered Learning

${ }^{*}$ Corresponding author.

How to cite this paper: Konopka, C. L., Adaime, M. B., Cunha, C., \& Dias, A. (2015). The Influence of Carl Rogers' Humanism on the Development of Positive Attitudes in Medical Students. Creative Education, 6, 2141-2151.

http://dx.doi.org/10.4236/ce.2015.620218 


\section{Introduction}

Society expects undergraduate degree egresses to exert their profession by integrating certain competencies, such as technical and scientific knowledge, skills, attitudes, behaviors and continuous professional development (Epstein \& Hundert, 2002: p. 227; Passi et al., 2010: p. 19). These assumptions are increasingly in evidence in health-related courses, especially in medical schools, through the competencies-based education (Fonseca \& Oliveira, 2013: p. 272).

The concept of attitude exists since the 1930s. Although definition is not always consensual, an attitude may be understood as a "predisposition or tendency of an individual or a particular social group to think, feel and act in different degrees of intensity and acceptance in order to respond in an organized, directed and consistent way to a certain object or issue.” (Crano \& Prislin, 2006, apud Ferreira, 2010: p. 55). Attitudes always include an evaluative dimension in a particular direction, and they may be expressed through a sense of positive or negative satisfaction, such as I like/do not like it or I agree/disagree with it. A positive attitude approaches the individual to an object or issue, and it is thus considered when the individual favorably responds to socially accepted standards inherent to the knowledge of a particular skill and/or professional practice (Eagly, 1992: p. 694; Wolf et al., 1989: p. 19).

The perception of the possibility of inferring attitudes has long encouraged psychology studies through measurement techniques, using the so-called attitude scales (such as Thurstone, Osgood, Stapel, Likert, Guttman, and Alpert, etc.). Nowadays, the determination of attitudes through researches in education represents a significant fraction of its scientific studies, in the search of the best curricular strategic planning in order to achieve the required competencies.

Attitudes are essential to mediate the application of knowledge and to the effective exercise of medical practice, which is usually featured by solving different problems brought by the patients (clinical complaints, changes in examinations, diseases and their complications, etc.). Since medical schools are aware of these medical-profession-inherent features, they included the learning of attitudes in the set of their educational goals, because they knew that without it, it would not be possible to create opportunities for the full and competent training of their students (DCNs, 2014: p. 8). More recently, attitudes acquired an even more central position in medical education due to the growing concern by higher education institutions and society with the social and humanistic aspects of this profession, since they affect health care quality (Santos \& Laros, 2014: p. 438; Passi et al., 2010: p. 20).

However, regarding medical education and social psychology, there are still uncertainties about the best way to introduce and evaluate the teaching and learning of attitudes in undergraduate courses (Bohner \& Dickel, 2011: p. 393; Eagly, 1992: p. 693). Many medical schools do not have these educational goals clearly defined. Others delegate this mission to humanistic-approach disciplines, although they allocate a small part of the curricular space for this purpose.

There are doubts regarding whether important and necessary attitudes to the professional practice can be taught or at least changed within the higher education environment, although it is known that attitudes are not stable and much less crystallized, at least regarding children and young people (Brito, 1996). Few papers report results on the specific influence of humanism and its contribution to the development of attitudes among students. Many studies show methodological shortcomings related to the subject of teaching and learning, such as the absence of a basic theoretical framework, and leave unanswered questions. Overall, the described experiences are heterogeneous; however, reports of difficulties in integrating humanistic themes to health teaching purposes are common (Rios et al., 2008: p. 120).

Fieschi et al. (2013) selected 60 papers in a medical humanism review in the Italian medical literature, over fifteen years (1996-2011). These papers were mostly written in narrative and theoretical discussion style. The authors review described four definitions for humanism in medicine, namely: the development of an empathic attitude, the development of interpretive skills, understanding and self-care, and finally, the acquisition of sense of ethics and responsibility. In addition, these authors concluded that the concern with humanism only affects a small part of the academic world, and that within this group there is a network for educators and mentors to share experiences, which remain limited to a small number of colleges. At the same time, during the fifteen-year review, they found that there has been no consolidation of knowledge based on significant results.

Interestingly, despite its increasing presence, there is still no clear and unanimous definition of the concept of humanism in medicine. Nevertheless, humanism has been gradually introduced in the curriculum of medical 
schools in the US, UK and Australia, with arguments that there is no better way to develop attitudes and behaviors essential for an empathetic and holistic approach to the patient, besides skills in communication and relationship, in decision-making for solving problems and also the ability to interpret the signs and symptoms of diseases (Kuper, 2006: p. 129; Perry et al., 2011: p. 142).

The first studies on the monitoring of values and attitudes in medical students began in the 1970s and 1980s. At that time, humanitarianism decrease was observed among students because medical training and activity were considered risk factors regarding the psychological aspect, since these professionals had to deal with pain, suffering and death (Rezler, 1974, apud Miranda, 2006: p. 11).

Different scales were built to measure attitudes that were more specific to medical education and activity in the recent decades. The first scale became widely used because it addressed the social, governmental and preventive aspects of medicine. It was described by Parlow and Rothmann in 1974, and named Attitudes Toward Social Issues in Medicine-ATSIM (Parlow \& Rothman, 1974: p. 385). Schwartz and Loten (2003, 2004) used the ATSIM scale and compared students from schools that used different teaching and learning methodologies. This comparison encompassed the traditional curriculum, the problem-based learning (PBL) methodology as well as the schools that opted for the mixed curriculum. The authors concluded that the most positive effect related to attitudes was found in schools that adopted the PBL methodology.

The psychologist Carl Rogers (1902-1987) pioneered the development of humanistic psychology and made significant contributions to the education field. His humanistic principles of authenticity, appreciation, trust and empathy emphasize human interrelations, consider individuals to exist in a continuous development process and recover the respect for human beings. According to Rogers, students should early develop their best attitudes, by learning to take a stance towards complex problems (Rogers, 1973). According to his principles, learning in the classroom depends on an enabling environment, in which teachers must assume humanistic attitudes towards their students. For this author,

[...] the person-centered teaching emphasizes teachers and students as individuals, and their relationship exists in a mutual respect atmosphere, in which it is up to the teachers to provide the students favorable conditions to develop their intellectual and emotional potential (Rogers, 2001: p. 52).

Rogers' main purpose regarding education is leading the students to abandon passivity and replace it by an active role in the student-centered learning. According to his humanist conception, learning contrasts with the traditional school approach, in which "the teacher is an actor playing a role, instead of a real person" (Rogers, 1986: p. 128).

Araújo and Vieira (2013: p. 103) found the presence of Carl Rogers' humanist conception in the educational practices of 41 health-field teachers in courses such as dentistry, medicine, physical therapy, biomedicine and nursing. According to the authors, the teachers showed modest humanistic trend concerning the preparation of lesson plans, the completion of the lessons planning, the content articulation for the students' training and concerning what they consider to be teaching and learning. As for the strategies for conducting classes and for the evaluation process, teachers primarily adopted traditional practices, with lectures and dissertation or objective evaluations. Thus, the authors concluded that the teachers' speech is humanist; however, the enduring pedagogical act is still the traditional education.

Humanistic education approaches may be found, explicitly or not, in laws, resolutions, opinions, educational projects, lesson plans and other documents. The Law of Directives and Bases for National Education (LDBNE, 1996), the Federal Republic Constitution (1988) and the National Curriculum Guidelines (NCG) related to undergraduate degree in Medicine (2014) are some examples of how humanistic ideas are strongly present in Brazil. The latest NCG for undergraduate degree in Medicine (2014) state that "the courses should have a studentcentered pedagogical project in which the students play an active role in learning, being supported by the teacher who plays the role of facilitator and mediator of the teaching-learning process", thus meeting the humanistic principles described by Rogers.

Therefore, the fundamental goal in medical education should be the full training of competent students who hold knowledge, skills, attitudes and behaviors. Thus, this is the moment for the following reflection: Specifically regarding attitudes, it is possible to achieve this goal by focusing the learning process on students-using Carl Rogers' theoretical framework of humanistic conception as basis-in order to comprehensively training these students by turning them into active subjects of their own learning and by seeking a significant experience? 
The current study attempts to answer this question by analyzing-according to Carl Rogers-the influence of humanism on the development and maintenance of positive attitudes in a sample comprising medical school students from the Federal University of Santa Maria (UFSM).

\section{Methodology}

This is a descriptive-analytical, observational, cohort (longitudinal) and qualitative and quantitative study. The research met the Guidelines and Standards Regulating Research Involving Human Beings (Resolution n. 196/ 96), and its project was previously approved by the Research Ethics Committee (CEP) at UFSM (n. 910086/ 2014), and received the Ethics Assessment Certificate (CAAE) n. 38742214.6.0000.5346.

\subsection{Study Population}

The studied population comprised 42 students from the $7^{\text {th }}$ semester of medical school at UFSM, who were regularly enrolled in the second semester of 2014.

\subsection{Featuring the Sample}

According to the previously established inclusion and exclusion criteria, the sample consisted of 42 students who agreed to voluntarily participate in the study. No sample loss was observed.

The sample was divided into two groups, namely Pre-intervention and Post-intervention groups, which featured the time before and after the intervention was performed.

\subsection{Procedure}

The intervention was represented by two simultaneous and distinct activities, both using Carl Rogers’ assumptions as theoretical reference. The first activity consisted of teaching practice based on positive attitudinal qualities such as authenticity, appreciation, trust and empathy, and the second activity involved the application of humanistic principles of significant learning.

Two-hour-duration weekly group meetings were set, totaling 15 meetings held from August to December 2014, according to the existing class division in the discipline of Medical-Surgical Clinic II of the Internal Medicine Department/Center of Health Sciences/UFSM.

The use of significant learning assumptions associated with the promotion of attitudes described by Rogers were inserted into the curriculum content in order to be part of the medical school program in the vascular surgery discipline. In addition to participating in the study, the students performed the other activities provided in the other disciplines, without any type of loss.

Under the mediation of a facilitator (teacher/researcher), a relaxed and student-centered environment was established during the meetings to promote interpersonal communication, debate ideas, raise questions, identify problems, stimulate creativity and to encourage self-learning and self-evaluation. In addition, there was the attempt of establishing an atmosphere with full freedom of expression to encourage the expression of feelings.

All the meetings were recorded by the researcher in a class diary/research report immediately after their completion. This record described the students' frequency, the activities they performed and the discussed issues, in addition to observations and pertinent personal impressions. The observations and records of events related to learning assumptions according to Rogers were particularly interesting, especially those related to the freedom of the content to be studied, the autonomy to learn, the perception of the "learning to learn", the active participation in debates, the creativity and self-confidence, as well as the reaction to the self-assessment. The students' receptivity to the attitudes of authenticity, appreciation, trust and empathy practiced by the researcher were also recorded in the report.

\subsection{Data Collection Instrument}

Participants were informed about the survey questionnaire. They were aware that the access to the data would be restricted to the researcher and that their identities would be kept anonymous. The students agreed to voluntarily participate in the study and showed compliance with the goals and procedures. All ethical guidelines were followed at the time the study was performed, including the obtainment of a formal consent. Students received in- 
structions about the Likert scale before they answered the questionnaire, which completion time was of approximately 30 minutes.

The sample was evaluated at two different times (early in the first and at the end of the last group meeting of each class, respectively before and after the intervention) by applying the Attitudes Assessment Questionnaire by Miranda (2006), who authorized its use.

According to Miranda (2006: p. 96), this questionnaire allowed defining an adequate scale with high internal consistency (Cronbach's alpha coefficient of 0.87 ), with validity and reliability for the measurement of attitudes in medical students.

The questionnaire comprised 102 propositions associated with a scale of answers for evaluating attitudes in order to measure to which extent medical students have favorable or unfavorable feelings towards the assertive propositions. The questionnaire items were answered by using a Likert-type response scale of five points, in which 1 means "I strongly disagree" and 5 means "I strongly agree" (Likert, 1932). Approximately half of the items were written in reverse and had their scores corrected during the analysis.

The questionnaire propositions were grouped into five different groups called dimensions: social, ambience, belief, knowledge and ethical.

According to Miranda's justification (2006: p. 23) for proposing the questionnaire,

[...] it is expected that individuals who have favorable attitudes to a particular topic possibly agree with items that express something positive about the issue, and those with negative attitudes will agree with items that express unfavorable aspects to the issue and disagree with those who emphasize positive points.

All the questionnaire propositions consisted of assertive sentences representing positive or negative attitudes towards the following aspects constituting the dimensions (object of assessed attitudes):

- Social dimension: aspects related to social responsibility, to the doctor-patient relationship and to communication (24 items, 12 representing positive attitudes and 12 representing negative attitudes);

- Ambience dimension: aspects related to eco-medicine and working environment (16 items, 8 representing positive attitudes and 8 representing negative attitudes);

- Belief dimension: aspects related to the perception of the physician's professional identity and to the understanding and respect for the diversity of beliefs within society (16 items, 6 representing positive attitudes and 10 representing negative attitudes).

- Knowledge dimension: aspects related to the physician's continuous learning, self-learning, evaluation in the learning and cooperative learning processes (30 items, 15 representing positive attitudes and 15 representing negative attitudes).

- Ethical dimension: ethical behavior aspects of the academic life, which are related to the Code of Medical Ethics (16 items, 8 representing positive attitudes and 8 representing negative attitudes).

\subsection{Attitudes Scale}

Values ranging from 1 to 5 were assigned to the statement categories, according to their level of agreement with each item. As for the results analysis, the responses to items that expressed positive attitudes were given values from 1 to 5, according to the intensity of the agreement expressed by the individuals. Similarly, responses to items that expressed negative attitudes scored from 1 to 5 , but in reverse. Thus, the individual score of each student was determined regarding the scale content, and it was analyzed according to the total score and in ranges.

Therefore, the average score ranged from 102 to 510 points in the 102 items of a scale constructed with score from 1 to 5 (102 vs. 1 and 102 vs. 5). As for the average score of the items composing the dimensions, the social dimension ranged from 24 to 120 points, the ambience, belief and ethical dimensions ranged from 16 to 80 points, and the knowledge dimension from 30 to 150. The scores obtained in the scale and in the dimensions were considered to be quantitative variables. However, when this total score was adopted as analysis criterion to interpret the attitudes, the score ranges associated with linguistic terms such as negative, conflicting and positive attitudes were used.

\subsection{Statistical Analysis}

Non-parametric statistical analysis was used due to the measurement level of the variables involved in the study. Since they were correlated samples in which there were two measurements for a single individual—before and 
after the intervention-McNemar test was used. Values equal to or less than $5 \%$ ( $p$-value, test value, $p \leq 0.05$ ) were considered to be significant. This test was used to compare proportions before and after the intervention in all the analyzed dimensions.

Pearson's correlation test was carried out to evaluate the correlation among the dimensions, since they were all normal when the Shapiro-Wilk Normality Test was applied. Regarding the correlation between the dimensions and age, the Spearman Rank correlation coefficient test was applied, since the age variable did not show normal distribution.

Initially, it was necessary reclassify the questionnaire regarding similar classes due to the sample size, in order to evaluate the association among the sociodemographic questionnaire dimensions and variables. Then, Fisher's exact test was used to analyze the associations.

Data were compiled in a database (Excel®, Microsoft Office 365) and statistical analyses were performed using Statistical Package for Social Sciences (SPSS) version 15.0 seeking for the answers to the goals set in the study.

\section{Results}

The sociodemographic characteristics of the sample are shown in Table 1. Sixty-nine percent (69\%) of them belonged to the age group $\leq 25$ years old, with predominance of women (66.7\%). It was found that almost $53 \%$ of the students attended private high school. Most parents showed higher degree of education, most notably with

Table 1. Sociodemographic characteristics of the sample of 42 medical school students from the $7^{\text {th }}$ semester, UFSM.

\begin{tabular}{|c|c|c|}
\hline Sociodemographic variables & $\mathrm{n}$ & $\%$ \\
\hline \multicolumn{3}{|l|}{ Sex } \\
\hline Male & 14 & 33.3 \\
\hline Female & 28 & 66.7 \\
\hline \multicolumn{3}{|l|}{ Age group } \\
\hline$\leq 25$ years & 29 & 69.0 \\
\hline$>25$ years & 13 & 31.0 \\
\hline \multicolumn{3}{|l|}{ High school type } \\
\hline Private school & 22 & 52.4 \\
\hline Public school & 20 & 47.6 \\
\hline \multicolumn{3}{|l|}{ Father's degree of education } \\
\hline High school & 15 & 35.8 \\
\hline Higher education & 27 & 64.2 \\
\hline \multicolumn{3}{|l|}{ Mother's degree of education } \\
\hline High school & 12 & 28.6 \\
\hline Higher education & 30 & 71.4 \\
\hline \multicolumn{3}{|l|}{ Complementary study source } \\
\hline Internet & 18 & 42.8 \\
\hline Books /journals & 24 & 57.2 \\
\hline \multicolumn{3}{|l|}{ Weekly study time } \\
\hline$\leq 5$ hours & 16 & 38.1 \\
\hline$>5$ hours & 26 & 61.9 \\
\hline
\end{tabular}


respect to the mothers, in $71.4 \%$ of the sample. Reading specific books or journals was the primary source used to complement the study in $57.2 \%$ of the cases, followed by the internet in almost $43 \%$ of the cases. Most students (61.9\%) reported active dedication to studies for more than five hours per week.

\section{Results Related to Attitudes}

The overall average of the Cronbach's alpha coefficient obtained in all dimensions both before and after the intervention was 0.55 .

The influence of the intervention on the change of attitudes in the social, ambience, belief, knowledge and ethical dimensions is shown in Table 2. Importantly, no student showed negative attitude in any of the analyzed dimensions both before and after the intervention.

It was found that the Rogerian intervention significantly changed attitudes related to the belief dimension ( $p=$ 0.025). The attitudes within the other dimensions (knowledge, ambience, ethical and social) were not significantly affected by the intervention $(p \geq 0.05)$. Moreover, it was found that, although the intervention did not significantly change the attitudes within the other dimensions, they showed general increase in their scores, showing tendency to become positive (constructive or socially accepted) between the beginning and the end of the study.

As for the social dimension, the intervention changed the attitude of two students, who showed conflicting attitude before the intervention and began to demonstrate positive attitude after the intervention. However, inversely, two students who had positive attitude before the intervention started to show conflicting attitude after the intervention. Both cases showed no statistical significance $(p=0.655)$.

Regarding the ambience dimension, although there was no significant difference $(p=0.625)$, three students changed from conflicting attitude before the intervention to positive attitude after the intervention. Only one student who showed positive attitude before the intervention changed to conflicting attitude after the intervention.

As for the belief dimension, it was observed that nine students who showed conflicting attitudes before the intervention began to show positive attitudes after it, and this difference was statistically significant $(p=0.025)$. Only one student who showed positive attitude before the intervention changed to conflicting attitude after it.

Regarding the knowledge dimension, it was observed that, although there was no significant difference ( $p=$ 0.625), three students changed from conflicting attitude before the intervention to positive attitude after the intervention. Only one student who showed positive attitude before the intervention changed to conflicting attitude after it.

As for the ethical dimension, the intervention did not significantly change the students' attitude. In addition, eight students who showed conflicting attitudes before the intervention began to show positive attitudes after it, although with no statistical significance. Conversely, seven students who showed positive attitudes before the intervention began to show conflicting attitudes after it, also with no statistical significance.

It is important to emphasize that the analysis of the attitudes regarding the ethical dimension found a bigger number of students with conflicting attitudes than in all the other dimensions (17/42, 40.5\%). In addition, the

Table 2. Distribution of dimensions and attitudes observed before and after the intervention in the sample of 42 medical school students from the $7^{\text {th }}$ semester, UFSM.

\begin{tabular}{ccccccc}
\hline \multirow{2}{*}{ Dimension } & \multicolumn{3}{c}{ Attitude before intervention } & \multicolumn{3}{c}{ Attitude after intervention } \\
\cline { 2 - 6 } & Negative & Conflicting & Positive & Negative & Conflicting & Positive \\
\hline Social & 0 & $2(4.8)$ & $40(95.2)$ & 0 & $2(4.8)$ & $40(95.2)^{* *}$ \\
Ambience & 0 & $5(11.9)$ & $37(88.1)$ & 0 & $3(7.1)$ & $39(92.9)^{* *}$ \\
Knowledge & 0 & $6(14.3)$ & $36(85.7)$ & 0 & $4(9.5)$ & $38(90.5)^{* *}$ \\
Belief & 0 & $13(30.9)^{*}$ & $29(69.1)^{*}$ & 0 & $5(11.9)^{*}$ & $37(88.1)^{*}$ \\
Ethical & 0 & $18(42.8)$ & $24(57.2)$ & 0 & $17(40.5)$ & $25(59.5)^{* *}$ \\
\hline
\end{tabular}

Note: The first value corresponds to the number of students, and the number in parenthesis corresponds to the percentage of the total sample students. ${ }^{*}$ Statistically significant difference, $p=0.025 ;{ }^{* *}$ Non-statistically significant difference, $p \geq 0.05$. 
ethical dimension also showed a bigger number of students who changed their attitudes from conflicting to positive and vice versa, under the influence of the intervention. One possible explanation for this finding may lie on the doubts that ethical issues often raise among students.

Overall, there was tendency of increase in positive attitudes in comparison to the conflicting attitudes in all the analyzed dimensions. However, this tendency was statistically significant $(p<0.05)$ just in the belief dimension.

Table 3 shows the correlation analysis among all the five dimensions investigated in the sample. There was positive and significant correlation among the social and the other dimensions. This correlation was stronger between social and ambience dimensions $(\mathrm{r}>0.50)$ and moderate among the social dimension and the others $(p$ $<0.49$ ). Another positive and significant moderate correlation was observed between the ambience and belief dimensions $(\mathrm{r}<0.49)$. The strongest and most significant correlation was observed between social and ambience dimensions, and the weakest correlation was observed between belief and ethical dimensions, although the latter was not statistically significant.

Table 4 demonstrates the correlation among age and the five dimensions of the study. It was observed that age showed significant positive correlation only in relation to the ambience dimension (Spearman rho correlation coefficient, $\rho=+0.332$ and $p<0.05$ ). The only negative correlation was observed between age and the knowledge dimension, however with the Spearman's rho correlation coefficient score close to zero $(\rho=-0.05)$, and without statistical significance. The other correlations between age and social, belief and ethical dimensions were positive, but without statistical significance.

The association between sociodemographic variables and attitudes in all five dimensions is shown in Table 5. Notably, no students showed negative attitudes in any one of the five dimensions analyzed. It was possible to infer that there was a significant association between the mother's degree of education and the ambience dimension $(p$-value $=0.018)$. The conflicting attitudes were related to students whose mothers attended only high school, and the positive attitudes to students whose mothers attended higher education. Likewise, it can be inferred that there was a significant association among the knowledge dimension and complementary study sources $(p$-value $=0.043)$. Students who reported using books and journals as the main complementary source of

Table 3. Correlations between the five dimensions in the sample of 42 students from the $7^{\text {th }}$ semester of the Medical School at $\mathrm{UFSM}^{1,2}$.

\begin{tabular}{cccccc}
\hline Dimensions & Social & Ambience & Knowledge & Belief & Ethical \\
\hline Social & \multirow{2}{*}{1.00} & $0.524^{*}$ & $0.419^{*}$ & $0.406^{*}$ & $0.458^{*}$ \\
& & $(<0.001)$ & $(0.006)$ & $(0.008)$ & $(0.002)$ \\
Ambience & & $0.303^{* *}$ & $0.347^{*}$ & $0.298^{* *}$ \\
& & $(0.051)$ & $(0.024)$ & $(0.057)$ \\
Knowledge & & & $0.289^{* *}$ & $0.266^{* *}$ \\
& & & $(0.063)$ & $(0.089)$ & $0.131^{* *}$ \\
Belief & & & 1.00 & $(0.407)$ \\
Ethical & & & & 1.00 \\
\hline
\end{tabular}

${ }^{1}$ Pearson's correlation test, with significance level $(p) \leq 0.05 \%$ or $5 \%$. The first value corresponds to the correlation coefficient score (r), and the number in parentheses corresponds to the $p$-value ( $p$-value or probative value); ${ }^{2}$ Criteria used to interpret correlation score of Pearson's r: from 0.10 to 0.29: weak correlation; from 0.30 to 0.49 : moderate correlation; from 0.50 to 0.99 : strong correlation. 1.0 : perfect positive correlation. * Statistically significant difference; ${ }^{* *}$ Non-statistically significant difference.

Table 4. Correlation between age and the five dimensions in the sample of 42 medical school students from the $7^{\text {th }}$ semester, UFSM.

\begin{tabular}{ccccccc}
\hline Dimension & Age & Social & Ambience & Knowledge & Belief & Ethical \\
\hline \multirow{2}{*}{ Age } & 1.00 & $+0.205^{* *}$ & $+0.332^{*}$ & $-0.05^{* *}$ & $+0.098^{* *}$ & $+0.282^{* *}$ \\
& & $(0.193)$ & $(0.032)$ & $(0.997)$ & $(0.539)$ & $(0.070)$ \\
\hline
\end{tabular}

Note: Spearman's rank correlation test, with significance level of $(p) \leq 0.05 \%$ or $5 \%$. The first value corresponds to Spearman's rho correlation coefficient score $(\rho)$, and the number in parenthesis corresponds to the $p$-value; ${ }^{*}$ Statistically significant difference; ${ }^{* *}$ Non-statistically significant difference. 
Table 5. Associations among the sociodemographic variables in all five dimensions (before intervention), in the sample of 42 medical school students from the $7^{\text {th }}$ semester, UFSM.

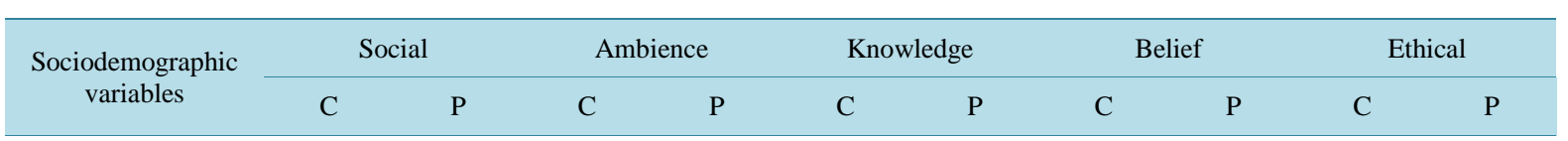

Sex

\begin{tabular}{|c|c|c|c|c|c|c|c|c|c|c|}
\hline Male & $\begin{array}{c}1 \\
(50.0)\end{array}$ & $\begin{array}{c}13 \\
(32.5)\end{array}$ & $\begin{array}{c}0 \\
(0.0)\end{array}$ & $\begin{array}{c}14 \\
(37.8)\end{array}$ & $\begin{array}{c}2 \\
(33.3)\end{array}$ & $\begin{array}{c}12 \\
(31.6)\end{array}$ & $\begin{array}{c}3 \\
(23.1)\end{array}$ & $\begin{array}{c}11 \\
(37.9)\end{array}$ & $\begin{array}{c}9 \\
(50.0)\end{array}$ & $\begin{array}{c}5 \\
(20.8)\end{array}$ \\
\hline Female & $\begin{array}{c}1 \\
(50.0)\end{array}$ & $\begin{array}{c}27 \\
(67.5)\end{array}$ & $\begin{array}{c}5 \\
(100.0)\end{array}$ & $\begin{array}{c}23 \\
(62.2)\end{array}$ & $\begin{array}{c}4 \\
(66.7)\end{array}$ & $\begin{array}{c}24 \\
(68.4)\end{array}$ & $\begin{array}{c}10 \\
(76.9)\end{array}$ & $\begin{array}{c}18 \\
(62.1)\end{array}$ & $\begin{array}{c}9 \\
(50.0)\end{array}$ & $\begin{array}{c}19 \\
(79.2)\end{array}$ \\
\hline
\end{tabular}

High school

\begin{tabular}{|c|c|c|c|c|c|c|c|c|c|c|}
\hline Public school & $\begin{array}{c}0 \\
(0.0)\end{array}$ & $\begin{array}{c}21 \\
(52.5)\end{array}$ & $\begin{array}{c}1 \\
(20.0)\end{array}$ & $\begin{array}{c}19 \\
(52.7)\end{array}$ & $\begin{array}{c}2 \\
(33.3)\end{array}$ & $\begin{array}{c}19 \\
(52.7)\end{array}$ & $\begin{array}{c}5 \\
(38.5)\end{array}$ & $\begin{array}{c}16 \\
(55.1)\end{array}$ & $\begin{array}{c}5 \\
(27.8)\end{array}$ & $\begin{array}{c}15^{* 4} \\
(62.5)\end{array}$ \\
\hline Private school & $\begin{array}{c}2 \\
(100.0)\end{array}$ & $\begin{array}{c}19 \\
(47.5)\end{array}$ & $\begin{array}{c}4 \\
(80.0)\end{array}$ & $\begin{array}{c}17 \\
(47.3)\end{array}$ & $\begin{array}{c}4 \\
(66.7)\end{array}$ & $\begin{array}{c}17 \\
(47.3)\end{array}$ & $\begin{array}{c}8 \\
(61.5)\end{array}$ & $\begin{array}{c}13 \\
(44.9)\end{array}$ & $\begin{array}{c}13^{* 4} \\
(72.2)\end{array}$ & $\begin{array}{c}9 \\
(37.5)\end{array}$ \\
\hline
\end{tabular}

Father's degree of education

$\begin{array}{lcccccccccc} & & 1 & 14 & 3 & 12 & 4 & 11 & 7 & 8 & 4 \\ \text { High school } & (50.0) & (35.0) & (60.0) & (32.4) & (33.3) & (30.5) & (53.9) & (27.6) & (22.2) & (45.8) \\ \text { Higher school } & 1 & 26 & 2 & 25 & 2 & 25 & 6 & 21 & 14 \\ & (50.0) & (65.0) & (40.0) & (67.6) & (66.7) & (69.5) & (46.1) & (74.4) & (77.8)\end{array}$

Mother's degree of education

\begin{tabular}{|c|c|c|c|c|c|c|c|c|c|c|}
\hline High school & $\begin{array}{c}0 \\
(0.0)\end{array}$ & $\begin{array}{c}12 \\
(30.0)\end{array}$ & $\begin{array}{c}4^{* 1} \\
(80.0)\end{array}$ & $\begin{array}{c}8 \\
(21.6)\end{array}$ & $\begin{array}{c}3 \\
(50.0)\end{array}$ & $\begin{array}{c}9 \\
(25.0)\end{array}$ & $\begin{array}{c}8^{* 3} \\
(61.5)\end{array}$ & $\begin{array}{c}4 \\
(13.8)\end{array}$ & $\begin{array}{c}4 \\
(22.2)\end{array}$ & $\begin{array}{c}8 \\
(33.3)\end{array}$ \\
\hline Higher school & $\begin{array}{c}2 \\
(100.0)\end{array}$ & $\begin{array}{c}28 \\
(70.0)\end{array}$ & $\begin{array}{c}1 \\
(20)\end{array}$ & $\begin{array}{c}29^{* 1} \\
(78.4)\end{array}$ & $\begin{array}{c}3 \\
(50.0)\end{array}$ & $\begin{array}{c}27 \\
(75.0)\end{array}$ & $\begin{array}{c}5 \\
(38.5)\end{array}$ & $\begin{array}{c}25^{* 3} \\
(86.2)\end{array}$ & $\begin{array}{c}14 \\
(77.8)\end{array}$ & $\begin{array}{c}16 \\
(66.7)\end{array}$ \\
\hline
\end{tabular}

Study sources

\begin{tabular}{|c|c|c|c|c|c|c|c|c|c|c|}
\hline Books/journals & $\begin{array}{c}0 \\
(0.0)\end{array}$ & $\begin{array}{c}24 \\
(60.0)\end{array}$ & $\begin{array}{c}3 \\
(60.0)\end{array}$ & $\begin{array}{c}21 \\
(56.7)\end{array}$ & $\begin{array}{c}1 \\
(16.7)\end{array}$ & $\begin{array}{c}23^{* 2} \\
(63.9)\end{array}$ & $\begin{array}{c}6 \\
(46.1)\end{array}$ & $\begin{array}{c}18 \\
(62.1)\end{array}$ & $\begin{array}{c}9 \\
(50.0)\end{array}$ & $\begin{array}{c}16 \\
(66.7)\end{array}$ \\
\hline Internet & $\begin{array}{c}2 \\
(100.0)\end{array}$ & $\begin{array}{c}16 \\
(40.0)\end{array}$ & $\begin{array}{c}2 \\
(20.0)\end{array}$ & $\begin{array}{c}16 \\
(43.3)\end{array}$ & $\begin{array}{c}5^{* 2} \\
(83.3)\end{array}$ & $\begin{array}{c}13 \\
(36.1)\end{array}$ & $\begin{array}{c}7 \\
(53.9)\end{array}$ & $\begin{array}{c}11 \\
(37.9)\end{array}$ & $\begin{array}{c}9 \\
(50.0)\end{array}$ & $\begin{array}{c}8 \\
\text { ( } 33.3)\end{array}$ \\
\hline
\end{tabular}

Weekly study time

\begin{tabular}{|c|c|c|c|c|c|c|c|c|c|c|}
\hline$\leq 5$ hours & $\begin{array}{c}2 \\
(100.0)\end{array}$ & $\begin{array}{c}14 \\
(35.0)\end{array}$ & $\begin{array}{c}0 \\
(0.0)\end{array}$ & $\begin{array}{c}16 \\
(43.2)\end{array}$ & $\begin{array}{c}2 \\
(33.3)\end{array}$ & $\begin{array}{c}14 \\
(38.9)\end{array}$ & $\begin{array}{c}5 \\
(38.5)\end{array}$ & $\begin{array}{c}18 \\
(62.1)\end{array}$ & $\begin{array}{c}8 \\
(44.5)\end{array}$ & $\begin{array}{c}8 \\
(33.3)\end{array}$ \\
\hline$>5$ hours & $\begin{array}{c}0 \\
(0.0)\end{array}$ & $\begin{array}{c}26 \\
65.0)\end{array}$ & $\begin{array}{c}5 \\
(100.0)\end{array}$ & $\begin{array}{c}21 \\
(56.8)\end{array}$ & $\begin{array}{c}4 \\
(66.7)\end{array}$ & $\begin{array}{c}22 \\
(61.1)\end{array}$ & $\begin{array}{c}8 \\
(61.5)\end{array}$ & $\begin{array}{c}11 \\
(37.9)\end{array}$ & $\begin{array}{c}10 \\
(55.5)\end{array}$ & $\begin{array}{c}16 \\
(66.7)\end{array}$ \\
\hline
\end{tabular}

Legend: C: Conflicting attitude, P: Positive attitude. Values in parenthesis denote percentages. Note: Fisher's exact test, considering a significance level of $p \leq 0.05 \%$ or $5 \%$. ${ }^{*}$ Statistically significant difference. ${ }^{1} p$-value: $0.018 ;{ }^{2} p$-value: $0.043 ;{ }^{3} p$-value: $0.033 ;{ }^{4} p$-value: 0.049 .

study related to positive attitudes on knowledge dimension, while those students who reported the internet as main the source were associated with the largest amount of conflicting attitudes. Additionally, it was found that there was a significant association among the mother's degree of education and the belief dimension $(p$-value $=$ 0.033). Students whose mothers attended only high school had conflicting attitudes regarding the belief dimension, while students whose mothers attended higher education showed positive attitudes in this dimension.

Furthermore, it was observed that there was a significant association between the type of school in which the student attended high education (public or private), and the ethical dimension ( $p$-value $=0.049$ ). It was found that the conflicting attitudes were related to students who have studied in private schools, while the positive attitudes, in turn, were related to students from public schools. Regarding gender, it was observed that the positive attitudes on ethical dimension were related predominantly to female gender. 
The analysis of the association among the sociodemographic variables and the attitudes in all five dimensions in the current study allowed establishing the general profile of the students with the best attitudes (only positive and socially acceptable ones). This profile comprised female students, whose father and mother have higher education degree. These students used books and journals as additional sources of study and reported that they dedicated a time greater than or equal to five hours per week in complementary studies.

\section{Discussion}

The medical practice diversification in the current socio-economic-social context determined the need for a medical profile capable of meeting the needs of society by giving effective solutions to the health problems of the population. From the realization that the emotional skills, as part of this professional profile, may be influenced by education, the search for the development of positive or socially approved attitudes became one of the goals of medical training. Therefore, researches emerged to determine the best measurement and intervention techniques for the curriculum diagnosis and strategic planning in order to achieve the competencies established for the professional practice.

The literature shows few papers reporting results on the influence of humanism on these competencies (knowledge, attitudes, skills and behaviors). Most of these studies show methodological shortcomings related to the subject of teaching and learning, such as the absence of a basic theoretical framework. They also leave many unanswered questions, especially regarding humanism contribution to the development of attitudes among students. Overall, the described experiences are heterogeneous; however, reports of difficulties in integrating humanistic themes to health teaching purposes are common.

The present research, based on assumptions of Carl Rogers’ humanistic learning, try to find a response if this methodology contributes to the development of positive attitudes among undergraduate medical students. The answer is yes, at least in part, regarding student's attitudes toward belief dimension. In this study, "belief” failed to be conflicting and significantly became positive with the Rogerian intervention performed. Despite the attitudes within other dimensions (knowledge, ambience, ethical and social) have not been influenced significantly by intervention, it was observed that these attitudes showed a general rise in their scores, showing a tendency to become positive (constructive or socially acceptable) between the beginning and end of the study.

At this point, an important issue concerns the relationship between belief and attitude. The concepts of belief, attitude and behavior are closely linked, and used very often to try to explain the formation of attitudes. The cognitive learning process generates the belief of an individual; that is to say, it represents the knowledge and conclusions — negative or positive - that this individual has about a certain subject or object. It is important to consider that not always "belief" in respect of a subject corresponds to reality; for example, if students believe that aspirin is used to effectively treat arterial leg thrombosis, they may extrapolate and widespread belief that all thrombosis in the human body can be treated by aspirin, which is not true.

There has been better understanding of the theory of attitudes in recent years. This fact allowed making them more predictive and measurable by means of psychometric techniques, which turned them into an important and complex research subject.

However, attitude research in medical education is not an easy task, given the complexity of factors involved. Despite the trend among medical schools to adopt increasingly active learning methodologies, delegating responsibility to the students to develop knowledge and psychomotor skills, at one point the teacher's performance has always been and will be essential: to serve as a model to students, encouraging them to develop positive attitudes and correct values.

Medicine-with its dynamic interactions among patient-disease-physician-society-easily enables the development and formation or change of attitudes, which allows exploring this subject in many ways within the medical education research field. The way teachers articulate the disciplinary content, the use of teaching and learning strategies_-such as Rogers' humanistic ones, the evaluation, the planning and the interaction with students may in part influence students' attitudes, as demonstrated by this study.

\section{References}

Araújo, E. S. C., \& Vieira, V. M. O. (2013). Teaching Practices in Health Area: Contributions for Reflexions from Carl Rogers. Revista da Associação Brasileira de Psicologia Escolar e Educacional, 17, 97-104.

http://dx.doi.org/10.1590/S1413-85572013000100010 
Bohner, G., \& Dickel, N. (2011). Attitudes and Attitude Change. Annual Review of Psychology, 62, 391-417. http://dx.doi.org/10.1146/annurev.psych.121208.131609

Brazil Ministry of Education (1996). Law of Directives and Bases of National Education (Law nº 9.394), Brasília. http://portal.mec.gov.br/arquivos/pdf/ldb.pdf

Brazil Ministry of Education (2014). National Curriculum Guidelines (NCG) of the Graduate Course in Medicine. Resolution CNE/CES 3/2014. Brasília: Official Diary of the Union, Section 1, 8-11.

Brazil Presidency of the Republic (1988). Constitution of the Federative Republic of Brazil. http://www.planalto.gov.br/ccivil_03/Constituicao/Constituicao.htm

Brito, M. R. F. (1996). A Study on Attitudes to Mathematics for Students of 1st and 2nd degrees. Free-Docency Thesis (Unpublished), Campinas: State University of Campinas.

Eagly, A. H. (1992). Uneven Progress: Social Psychology and the Study of Attitudes. Journal of Personality and Social Psychology, 63, 693-710. http://dx.doi.org/10.1037/0022-3514.63.5.693

Epstein, R. M., \& Hundert, E. M. (2002). Defining and Assessing Professional Competence. Journal of the American Medical Association, 287, 226-235. http://dx.doi.org/10.1001/jama.287.2.226

Ferreira, M. C. (2010). Contemporary Social Psychology: National and International Main Trends and Perspectives. Psicologia: Teoria e Pesquisa, 26, 51-64. http://www.scielo.br/pdf/ptp/v26nspe/a05v26ns.pdf

Fieschi, L., Matarese, M., Vellone, E., Alvaro, R., \& De Marinis, M. G. (2013). Medical Humanities in Healthcare Education in Italy: A Literature Review. Annali dell'Istituto Superiore di Sanità, 49, 56-64.

Fonseca, A., \& Oliveira, M. C. (2013). Competency-Based Education. Arquivos de Medicina, 27, 272-277.

Kuper, A. (2006). Literature and Medicine: A Problem of Assessment. Academic Medicine, 81, 128-137. http://dx.doi.org/10.1097/00001888-200610001-00032

Likert, R. A. (1932). Technique for the Measurement of Attitudes. Archives of Psychology, 22, 1-55.

Miranda, S. M. (2006). Investigation of Attitudes in Undergraduate Medical Students Considering the National Curriculum Guidelines (pp. 9-154). Master's Thesis, Florianópolis: UFSC. https://repositorio.ufsc.br/bitstream/handle/123456789/89298/225989.pdf?sequence=1

Parlow, J., \& Rothman, A. I. (1974). ATSIM: A Scale to Measure Attitudes towards Psychosocial in Health Care. Journal of Medical Education, 49, 385-386. http://dx.doi.org/10.1097/00001888-197404000-00012

Passi, V., Doug, M., Peile, E., Thistlethwaite, J., \& Johnson, N. (2010). Developing Medical Professionalism in Future Doctors: A Systematic Review. International Journal of Medical Education, 1, 19-29. http://dx.doi.org/10.5116/ijme.4bda.ca2a

Perry, M., Maffulli, N., Willson, S., \& Morrissey, D. (2011). The Effectiveness of Arts-Based Interventions in Medical Education: A Literature Review. Medical Education, 45, 142-148. http://dx.doi.org/10.1111/j.1365-2923.2010.03848.x

Rios, I. C., Lopes Jr., A., Kaufman, A., Vieira, J. E., Scanavino, M. T., \& Oliveira, R. A. (2008). The Integration of the Medical Humanities in the Medical Faculty of São Paulo University. Revista Brasileira de Educação Médica, 32, $112-121$. http://www.scielo.br/pdf/rbem/v32n1/15.pdf http://dx.doi.org/10.1590/S0100-55022008000100015

Rogers, C. (1973). Freedom to Learn (2nd ed.). Belo Horizonte: Interlivros.

Rogers, C. (1986). Freedom to Learn: A View of What Education Might Be (2nd ed.). Porto Alegre: Artes Médicas.

Rogers, C. (2001). On Becoming a Person (4th ed.). São Paulo: Martins Fontes.

Santos, W. S., \& Laros, J. A. (2014). Revision of a Scale to Measure Attitudes of Medical Students. Avaliação Psicológica, 13, 437-445. 